\title{
SUGGESTIONS FOR FURNISHING A DINING ROOM.
}

By Harold Le Baron, New Auburn, N. Y.

I would suggest your using a simple pattern rug of soft green and brown tone; a Brussels rug will always prove a serviceable one for a dining room as it is very easy to keep clean. It will require some looking to get an inoffensive small pattern. The wall paper should be a soft sage green; small two tone stripe is preferable; the woodwork to be ivory keyed to the paper. The curtains should be a plain net or scrim hung apron length. These would probably be about $\$ 3.50$ a pair if the material were bought and made up. If over-draperies are desired, a small figured tan and green mercerized silk would look very well. These should be shirred at the top with a 1-inch heading, and shirred on a 3-8-inch rod. They should hang perfectly straight and tend to hold the colors of the wall and rug together as much as possible. With brass goods these curtains ought to be made anywhere from $\$ 5.00$ to $\$ 7.00$.

With this as a setting, the matter of furniture is largely the taste of the customer. If it were possible, I should put in a perfectly plain set of mahogany of good Sheraton lines, using a dining table, six dining room chairs covered in a dull sage green hair cloth, a buffet ( 60 inches long at least) and a serving table. A set like this should cost in the neighborhood of $\$ 225.00$. There are some very nice Sheraton sets, such as I have just described, on the market. Of course you can vary these with inlay and run the price up into the thotssands if you wish. There is one thing in particular that you will note, and that is that a china cabinet has not been mentioned. Decorators are eliminating this as fast as possible as commercial show cases are not the proper thing for a home. A cabinet is simply used to display your best glass and china which on state occasions is all removed and leaves your cabinet looking its worst, when it should really be at its best.

With the shell of the room as I.described it, almost any furniture of simple design could be used to advantage. The sage green wall paper makes a neutral background for either mahogany or oak. I would advise, however, if you intend using oak not to use the golden oak and mission styles, both of which have become exceedingly common. In case oak is used, it would be better to adhere strictly to a period style throughout for that will always be in good taste. 